\section{Autonomía y dignidad de los adultos mayores en Chile}

\section{Autonomy and dignity of older adults in Chile}

\section{Señor Editor,}

En el contexto de la pandemia en Chile, las autoridades sanitarias establecieron cuarentena obligatoria para los mayores de 75 años, afectando a más de 1 millón de personas. A diferencia de lo ocurrido con las personas de menor edad, no se consideró que los adultos mayores fuesen capaces de asumir la responsabilidad de su autocuidado, resultando de esta manera una medida arbitraria e injustificada. Es innegable que la pandemia evidenció inequidades e injusticias sociales, sin embargo, poco se ha dicho acerca de la falta de valoración y respeto por la autonomía de los adultos mayores la cual, a través de muchos hábitos sociales, es una constante en la vida de muchos de ellos.

Según el censo de 2017, los mayores de 60 años representaban $16,2 \%$ de la población con tendencia en aumento -el índice de envejecimiento pasó de 55,8 en el 2006 a 100,4 en el 2017². Esto ha planteado múltiples desafíos: mejorar el sistema de pensiones y enfrentar las cargas de un "sector pasivo" en crecimiento; asumir los costos en salud asociados al incremento de enfermedades crónicas; lograr un ámbito laboral inclusivo; definir nuevos roles en la comunidad; y desde las familias, asumir el cuidado con las dificultades que esto implica. Las soluciones se han encarado desde la visión de que los adultos mayores tienen necesidades de cuidado, pero no se han tenido en cuenta sus derechos, sus preferencias y sus individualidades. Solemos tomar, desde nuestros propios valores, decisiones que afectan su calidad de vida, los cuales probablemente difieran radicalmente de los valores de ellos. Si analizamos los resultados de una encuesta sobre calidad de vida en Chile en el período 2007-2016 incluyendo a más de dos mil adultos mayores, vemos que más del $20 \%$ admitió haber sufrido un trato injusto debido a su edad en establecimientos municipales e instituciones de salud. Cuando se les preguntó cuál era su principal preocupación, la "dependencia de terceros" figuró en primer lugar, superando a la pérdida de familiares, el temor a enfermarse, $\mathrm{o}$ a la soledad ${ }^{2}$. El hecho de que su principal preocupación sea depender de otros tiene dos aristas: el deseo de no representar una carga para su familia y el temor a perder su autonomía. De las anteriores, la pérdida de la autonomía es la más sufrida, ya que incluso aquellos que liberan a sus familias del cuidado diario aceptando su traslado a residencias de mayores, continúan sufriendo esta pérdida.

En 2017 Chile ratificó la Convención Interamericana sobre la Protección de Derechos de las Personas
Mayores, reconociéndolos como plenos sujetos de derechos. En el mismo año, se estableció el Código de Ética del SENAMA definiendo su misión: "Fomentar el envejecimiento activo y el desarrollo de servicios sociales para las personas mayores, cualquiera sea su condición, fortaleciendo su participación y valoración en la sociedad, promoviendo su autocuidado y autonomía, y favoreciendo el reconocimiento y ejercicio de sus derechos; por medio de la coordinación intersectorial, el diseño, implementación y evaluación de políticas, planes y programas"3. Sin embargo, como se evidenció en esta pandemia, la autonomía, el reconocimiento y el ejercicio de los derechos de los ancianos no han sido una prioridad a la hora de definir políticas públicas.

La dignidad humana, entendida como el valor ontológico de la persona, es inherente a la misma y como tal debe ser siempre respetada. Sin embargo, existen situaciones de mayor vulnerabilidad, como el envejecimiento, en las cuales la dignidad puede verse amenazada, debido a la falta de reconocimiento de la autonomía. Ésta se relaciona íntimamente con la dignidad, ya que para poder realizar actos autónomos deben estar aseguradas las mínimas condiciones de respeto por la dignidad y, a su vez, el respeto por la autonomía es necesario para honrar la dignidad de esa persona ${ }^{4}$.

Es interesante el análisis que hace Bernadette Puijalon sobre la autonomía de los ancianos y la dependencia ${ }^{5}$. Menciona una "autonomía funcional", la cual va decreciendo de forma progresiva según el grado de dependencia, y la "autonomía decisional" relacionada con la autodeterminación y la dignidad. Ésta es la que se asocia al proyecto de vida, y es la que los ancianos necesitan que se les reconozca, cuando la autonomía funcional se va deteriorando ${ }^{5}$. Cuando erradamente se relaciona la autonomía funcional con la dignidad, ésta se ve amenazada por vulneración de la autonomía decisional. En la cultura actual, en que la independencia es el ideal, se plantean desafíos éticos en cuanto al respeto por la autonomía y la dignidad de los ancianos. Sólo aceptando la interdependencia de la que todos somos parte, podríamos ocuparnos en serio de la calidad de vida de los adultos mayores. Reducirlos a meros receptores de cuidados, es negarles su experiencia existencial del envejecimiento.

Especial cuidado debiese tenerse en la consulta clínica, a pesar de que el paternalismo es rechazado ampliamente como modelo, éste continúa ejerciéndose en la práctica médica con los ancianos. Son frecuentes las conspiraciones del silencio, la infantilización, la ausente promoción de su autonomía, incluso sabiendo que esto resulta maleficente provocando daños morales e impactando negativamente en la adherencia a tratamientos. El paternalismo que se ha impuesto a los ancianos es discriminatorio, injusto y maleficente, porque atenta directamente contra la autonomía y dignidad.

El capítulo final de la biografía de cada persona 
debiese ser escrito en el marco de la libertad que exige el ejercicio de su autonomía, basado en el respeto a su dignidad. Podremos implementar programas asistenciales y capacitar técnicamente a los cuidadores, pero nada logrará un impacto real en la calidad de vida de los ancianos si no hay un replanteamiento de los valores que tenemos como sociedad. Si no son legitimados desde su experiencia vital, tendremos una sociedad en gran parte sometida, acallada, infantilizada e infeliz, una sociedad injusta.

Esto merece ser considerado una ética de mínimos que como tal se rige por los principios de No maleficencia y de Justicia que son parte de los acuerdos básicos que como sociedad debiésemos consensuar.

María Laura Aued ${ }^{1}$

${ }^{1}$ Universidad del Desarrollo. Santiago, Chile.

\section{Referencias}

1. Resultados Encuesta Casen 2017. Disponible en: www. observatorio.ministeriodesarrollosocial.gob.cl
2. Caja Los Andes, Pontificia Universidad Católica de Chile. Chile y sus mayores: 10 años de la encuesta calidad de vida en la vejez. 2016. Disponible en www.senama.gob.cl

3. Servicio Nacional del Adulto Mayor. Código de Ética. 29/3/2017. Disponible en: www.senama.gob.cl

4. Román B. Euthanasia: Between Personal Moral and Civics Ethics. En: Kure J (ed). Euthanasia: The good death Controversy in Humans and Animals. IntechOpen; 2011. ISBN-10 9533072601.

5. Puijalon B. Autonomía y vejez: un contexto cultural, un enfoque político, una propuesta filosófica. En: Autonomía $y$ dependencia en la vejez. Cuadernos de la Fundació Victor Gríflos i Lucas. Vol 16. p 8-28.

Correspondencia a:

María Laura Aued

Camino del Monasterio 9428

Lo Barnechea. Santiago, Chile.

lauriaued@gmail.com 